manœuvres which have been shown, berond reasonable dowabt, to be of realh value. Discredit can only be brought or a rational method of anaesthesia by its too ardent application to a region to which it is very questionably saited.

A modification of Labat's method was used in 32 cases, with good results in 11 . Of these, 4 were partial gastrectomies, 3 gastro-enterostomies, and 1 a choledochotomy. It is impossible to be sure, however, just how much of the lesult was dae to the araesthesia of the abdominal swmpathetice nerves, which Labat's method induces.

The most imporitant result of regional anaesthesia is demonstrated rather b.y experience than figures. It is that in almost all cases the partient is the better for his regioual anaesthetic, and even if inhalation anaesthesia is also meeded, the patient is held with a minimum of nitrous oxirle or ethylene of ten sufficient only to abolish conscionsness.

\section{Reagtions to Regional Anaesthesia.}

These are easily induced unless strict watch is kept on the patient and the variøus signs noted. It was the rule in all the cases of the present series for a morse to sit at the patient's head and record the pulse. In kead, spinal cord, and abdominal: cases she also took the blood pressure. All these were recordedi on a sheet of paper which the administrater eould see and son anoid alarming the patient by verbal inquiries. The aurse also engaged the patient in conversation and withdrew his attention from the manipulations.

A reaction may be due either to the adrenaline injected or to the novocain, or both. An adrenaline reaction is early, a norocain reaction late. The elements of an adrenaline reaction in the order of their appearance are: (1) increased respiration, (2) rapid purse, (3) palpitation, (4) apprehensive excitement, (5) tremor, (6); sweating, (7) dyspnoea, and (8) precordial pain. The last two, unlike the others, are late in onset. Any three of the first six constitute a marked reaction; the last two are happily as rare as ther are serious. The elements of a norocain reaction are those of spinal anaesthesia: slow pulse, fall in blood pressure; pallor, cyanosis, nansea, and nomiting.

The treatment for either type of reaction is that of prevention. Safety is ensured by slow injection and cessation as soon as the reaction appears. The effect mears off in a few minutes. It is not cumulative and injection mas proceed after an interval. In the event of a severe adrenaline reaction, oxygen containing 5 per cent. of carbon dioxide is given. This relieves the air hunger and anginal pain. More than 30 minims of adrenaline should never be given to one patient. There was onl one severe adrenaline reaction in the present series. That was in the case of a patient whe was afterwards found to have a family history of capillary atonicity. Both blood pressure and pulse rate were abnormally low, and his type would now be considered unsuitable for regional anaesthesia.

An ampoule containing 3 grains of caffeine, 7 grains of sodium benzeate, and $\Theta .025$ glain of strychnine should be in readiness in the event of a severe novocain reaction. For severe cases of pallor, nausea, and slow pulse, from 5 to I0 minims of adrenaline are injected.

A certain measure of success may be attained by practice of the technical methods herein detailed. To improve on that and to reduce failure to a minimum, eareful study of the anatomy of the region is essential. It is necessary to visualize the fiedd in perspective, and to be prepared for those variations from normal topography and relations which are not to be dealt with by rule of thumb.

\section{BIBLJOGRAPHY.}

1. Braun, Heinrich : Local Anesthesia; its Seientific Basis and Practical $\boldsymbol{U}$ se. Second American edition, from sixth revised German edition. Philadelphia: Lea and Febiger, 1924.

2. Gwathmey, J T. : Anesthesia. Seeond revised edition. New York: Macmillan, 1924

3. Labat, Gaston: Regional Anesthesia; its Teclinic and Clinical Application. Philadelphia: W. B. Saunders, 1922.

4: Meeker, W. R. : Lancet, 1924, xliv, pp: 1-6.

5. Idem : Ani. Surg., 1924, laxix, pp. 124-129.

6. Meeker, W. R., and Frazer, E. B.: Surg., Gyn. and Obstet., 1922, xxxr, pp. 801-812

T. MLeker, W. R., and Hundling, H. W.: Surg., Gyn. and obstet. 924. xxxviii, pp. 805.818.

Q Meetier, W. R., and Seholl, A. J. : Ann. Surg., 1924, 1xxx; pp. 739-772

\section{NODAL FEVER.}

(ERYTHEMA NODOSUM, ERYTHEMA MULTIFORME.)

\section{BY}

\author{
ALFRED AUSTIN LENDON, M.D.LoND., \\ ADELAIDE, SOUTH AUSTRALIA.
}

\section{Phelmararay.}

Is 1905 I published a book which bore the title Nodal Fever; quite reeently Dr. G. F. Walker of Leeds has asked for my puesent views on this subject, and I will hero sum up the results of further observations made during the past two decades. With respect to my parrum opus I may mention that, although the criticisms were very complimentary and friendly, the general verdict was the Scottish one of " Not proven."

Briefly stated, my contention was that erythema nodosum is not merely an affection of the skin, but an acute specific fever, met with, and best studied, in ordinary general practice. Evidence was addueed to show that it had a distinct prodromal stage, a stage of eruption, and a period of convalescence; that relapses occurred, and that second attacks had been noticed after an interval of several Fears. The theopy advoeated by Br. (afterwards Sir) Stephen Mackenzie nearly forty years ago, that it is a manifestation of rheumatism, was combated; an explanation of the arthritie symptoms was suggested; and Trousseau's dictum that erythema nodosum is a distinct disease from erythema papulatum was disputed. Finally, $I$ ventured to rename the disease "nodal fever" (febris nodesa).

Wy attention was first directed to this complaint when I graduate in 1879. I was attending at the time a brother, aged 16, whose attack as regards the copiousmess of the rash, the degree of the accompanying pyrexia, and the prolongation of convalescence, was as severe as any 1 have: ever seen since; it was something very different from the mild cases $I$ had observed in hospital ont-patient practice. I settled in Adelaide in 1883, and during the next seven vears met with thirteen more cases. In 1886 I was struek by the coincidenee of two cases of erythema notbsum ocenring in the same houschold at the same time, bat divel not regard it as more than a coincidence. In the following year $F$ had a child, aged 4 years, under my care for several days with a mild feverish attack, and had suspected typhoid fever-because of its prevalence at that time; when it turned out to be erythema nodosum, the resemblance of this prolonged peried of malaise and pyrexia to the ordinary prodromal stage of many of the areate speeific fever's inmediately struck me, and the chain of evidence scemed fairly complete. These observations were confirmed in subsequent cases, and in $1890 \mathrm{I}$ wrote a paper ${ }^{1}$ entitled "Erythema nodosum, an acute speeific fever." The vofume Nodial Fever, based upon 63 cases, appeared fifteen years later, and was merely an elaboration of $\mathrm{my}$ former paper.

Fn this present communieation it is proposed to deal with the subject by showing the general resemblance the symptoms and course of noflal fever bear to other acute specific fevers, by bringing forward fresh evidence pointing to its infectious nature, and by diseussing its suggested relationship to other diseases, and the views therean of other writers.

\section{STathetres.}

The first point to which $I$ would draw attention is the age ineidence (excluting cases seen in the Children's Hospital); there were-

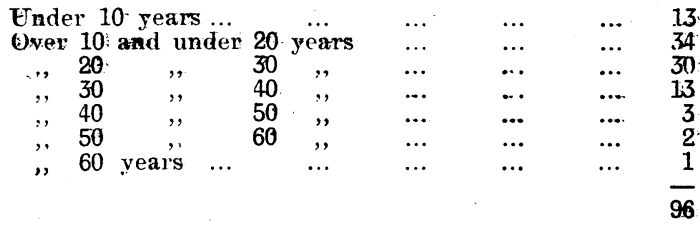

Roughly speaking, 94 per cent. were under the age of 40 years and 6 per cent. oxer. that age. If we accept 14 years as the average age of puberty in both sexes, and 
48 as the approximate date of the climacteric in woman, we find the cases grouped as follows:

$$
\begin{array}{lccccr}
\text { Under the age of puberty ... } & \ldots & \ldots & \ldots & 27 \\
\text { Between puberty and the climacteric } & \ldots & \ldots & 66 \\
\text { After the climacteric } \quad \ldots & \ldots & \ldots & \ldots & 3 \\
& & & & & 96
\end{array}
$$

The youngest patient was $2 \frac{1}{2}$ years of age, the oldest was 69 .

The influence of sex combined with age is interesting: taking all cases I find-

$$
\begin{aligned}
& \text { Under the age of puberty, } 18 \text { males, } 17 \text { females. } \\
& \text { Over " } " \frac{4}{22} \text { males, } 102 \text { females }=124 .
\end{aligned}
$$

The influence of season is very slight.

$$
\begin{array}{cllll}
\text { In the first quarter of the year there were } & \ldots & 29 \\
\text { " second " } & \text { " } & \text { " } & \ldots & 25 \\
\text { " third " fourth ", } & \text { " } & " & \ldots & 30 \\
\text { " } & & & \cdots & 34 \\
& & & & 118
\end{array}
$$

As regards social state, of those who had attained their majority 38 were single and 18 married. Of 46 adult women the majority were engaged in domestic occupations, but 7 were hospital nurses, and 7 were school teachers, whilst one man and one girl were medical students, and another male was a teacher.

\section{Symptoms and Cotrse.}

Instead of describing a series of individual cases $I$ shall attempt to draw a composite picture of the complaint, dealing separately with the prodromal, the eruptive, and the convalescent stages. I must premise, however, that cases are met with of varying degrees of severity as regards the general symptoms and the extent of the eruption, as well as of the accompanying pyrexia.

\section{Prodromal Stage.}

It is not unusual for medical advice to be sought in this stage, when one may meet with most of the ordinary symptoms comprised under the term "malaise," such as headache, shivers, and temperatures ranging as high as $103^{\circ}$; pains in the limbs and joints, stiffness, or a tired feeling as though the limbs were of no use; one patient felt as if she had walked miles. In about 16 per cent. of cases a sore throat is mentioned as an early symptom, but the objective signs in the throat are very slight; at other times there is a complaint of naso-pharyngeal or tracheo-bronchial catarrh; more rarely disturbances of the alimentary canal attract attention. A correct diagnosis at this stage is seldom possible, unless amongst the other symptoms ocular phlyctenulae are noticed; in two such instances ${ }^{2}$ I did prophesy that erythema nodosum would appear, and my prophecy turned out to be correct; on one or two other occasions, even without the presence of this valuable sign, 1 have suggested nodal fever as a possible diagnosis when no adequate explanation could be found for the prolonged high temperature, and I have been justified by the event. It will illustrate better, I think, the puzzling nature of the prodromal symptoms if $I$ enumerate some of the various suspicions that have been aroused-rheumatic fever, enteric fever, influenza, tuberculous meningitis, hepatitis; these are some of the "shots" at diagnosis made, not by the patient's friends, but by the medical attendant.

The duration of this prodromal stage when well marked, as it was in a third of my second series of cases, appears to average about twelve days, and its extreme limits to range from seven to seventeen days, as far as I can judge. This corresponds very closely with my previous estimate in 1904 . A very distinct feature of the prodromal stage is an exacerbation of the symptoms on the third or fourth day preceding the appearance of the rash; this was noticeable in 40 per eent. of my second series. The incubation period, moreover, is occasionally preceded by a considerable period of vague ill health, extending over some weeks or even months, and demanding treatment. The only inference orie could venture to draw is that debility, attended with dyspepsia and anaemia, may possibly render the sufferer more vulnerable to an attack of nodal fever; on the other hand, other patients seem to have contracted it when in robust general health.
Stage of Eruption.

The question of diagnosis is seldom likely to occur in this stage. The individual spots of erythema nodosum on the shins are easily recognized, and I have been' careful to exclude cases of erythema papulatum or erythema multiforme which failed to show at least one typical node on the regs. In a patient seen with Sir Joseph Verco in 1917, where no erythema nodosum or phlyctenulae could be found, there was an abundant rash of the appearance of erythema papulatum and erythema tuberculatum, together with diffuse blotches several square inches in area, but in this case an explanation was found in the fact that the patient was taking potassium bromide for epilepsy; the rash disappeared as soon as the drug was discontinued.

With respect to the appearance of the rash, I may say generally that the characteristic nodes, oval in shape, with their long axes more or less parallel to the limbs, and seldom or never transverse, are mainly seen on the legs. They used to be described as situated chiefly along the shins, but they have no special affinity for subcutaneous bony surfaces, and they may be seen just as much over the rest of the legs. To a less extent this oval shape may be noticed in nodes on the forearm, but elsewhere, round the knees for instance, the skin lesions are generally circular and may range from papules the size of peas to blotches two or three inches in diameter. Many of these spots seen apart from a genuine case of erythema nodosum would be described as erythema papulatum or erythema tuberculatum. I wish to stress this point because, whilst erythema nodosum may predominate, or appear alone, in a given case, the eruption in severe cases is usually a mixed one, and the rarer, though not very uncommon, appearance also of erythema iris, or erythema gyratum, establishes definitely, in my opinion, the multiform character of the nodal fever rash.

The manner in which these spots appear and fade into bruise-like swellings, lasting sometimes for five or six weeks, or even, faintly, for two or three months, need not be described, as it is so familiar; but I may emphasize the fact that the pain and tenderness associated with the spots may persist also for a long time, and that the lumps may be felt long after all colour has faded, whilst the pain and the purple tint may be revived by hanging down the limbs some time after these symptoms had apparently disappeared in the convalescent stage. I do not propose to dwell upon the appearance of the spots elsewhere than on the limbs, but the body, the face, and neck may all be attacked.

The duration of the eruption varies from a few days to some weeks. Besides the fading bruises, a crinkled skin and some desquamation may be roticed, but never suppuration or ulceration, though pustular spots of staphylococcal origin are sometimes accidentally associated. The spots may appear in relays, so that the eruption may be seen in all stages at the same time; or fresh spots may appear when the patient is convalescing, with intervals of from twelve to twenty-five dars between the two crops; one lady reported from South Africa ${ }^{3}$ that fresh spots had been constantly recurring for nearly a year.

As regards the general symptoms of the eruptive stage, one need only say that they are such as are usually associated with fever and the accompanying toxaemia, and that whilst usually they preserve some ratio of severity to the copiousness of the rash, they often seem less severe than during the prodromal stage.

Two special symptoms should be mentioned. One is somewhat rare, and I have termed it "Verco's sign," as it was first pointed out to me by Sir Joseph Verco in 1892.4 It consists of subungual striae or dots of haemorrhage, and may be seen both on the hands and the feet; in my second series of cases I met with it five times-that is, about once in twelve cases. The other symptom is much more common, and consists of one or more phlyctenulae; they are seen on the ocular conjunctiva near the margin of the cornea like tiny spots, or pimples, with a leash of blood vessels like a comet's tail spreading out towards the periphery of the eyeball; generally they are seated over the insertions of the inner or outer recti, but similar spots may be seen on the palpebral conjunctiva near the tarsal edge. It has, as I have already mentioned, a diagnostic importance in the prodromal stage; from its frequency-it occurred in 40 per 
cent. of my cases-it establishes itself as an integral part of the disease, and in my opinion is undoubtedly the manifestation of the rash on a mucous membrane. I have not seen a similar thing in the nose or mouth, but in a fatal case of erythema papulatum which I reported ${ }^{5}$ there were spots of superficial ulceration in the mouth. If, then, lesions appear on the visible mucous membranes as well as upon the skin, it is not, I think, a far-fetched idea to suggest that the pain complained of in the joints in both the prodromal and the eruptive stages may be due to a " node" developing on srnovial surfaces. Here I may mention a piece of evidence that true skin is not an essential basis for the appearance of nodes; for $I$ have seen them on a wide scar over the knee where no true skin tissue appeared to be left. In three or four cases only the glands of the neck have been noticed to be enlarged.

Stage of Convalescence.

In this stage the chief features are the marked depression and debility, whilst a few have complained of "rheumatism" subsequently. In one case weakness of the limbs persisted for which massage was necessary some eight months after the illness; in an elderly lady the saphenous veins in both legs became plugged.

\section{Second Attacks.}

I have recorded ${ }^{6}$ four cases of second attacks, and now I can add fire more. The interval between the two attacks ranged from one to sixteen years, but the average was almost five years. One patient, a hospital nurse, had three definite attacks within two vears. Two other instances of errthema nodosum were followed at intervals of twelve and eighteen years respectively by attacks of erythema papulatum in which no definite spot was discovered which by itself could be called erythema nodosum.

\section{Ultimate History of Patients.}

Amongst those who have since died one suceumbed to an appendix operation, another died at 75 of apoplexy, and a third at 82 of mitral disease. Morbus coxae, pulmonary tuberculosis, tuberculous meningitis each claimed one victim, and another ease suecumbed to erythema papulatum. of the rest, one was operated upon for exophthalmic goitre and one became insane (her mother and sister had committed suicide); in one girl, whose brother was invalided home from the war with phthisis, there is a suspicion of apical tuberculosis; two other patients are liable to a vague sort of rheumatism unattended with fever.

\section{The Evidence of Infection.}

I have previously reported ${ }^{7}$ several examples of apparent infection convered from one patient to another, and now, with my additional cases, I have collected altogether ten such instances. In five of these two children in one family have been seen with the eruption coming out at intervals of from one to nine days, with an average of four days; such cases might be explained by the suggestion of a possible family predisposition, or of exposure to the same exciting cause at about the same time. Family predisposition cannot, in my opinion, be entirely ignored, because in one family I have notes of five grown-up young women contracting the disease at intervals of from one to seven years; four of them were sisters and the fifth a first cousin. Here the further question of a possible "carrier" comes in, and the fact of a patient being a carrier might explain the relayses and second attacks to which I have drawn attention; one of the sisters just mentioned had a second attack. As another instance of such possible family predisposition, or of "carrying" the germ, there is the case of Mrs. A., who had erythema nodosum as a girl of 16 soon after measles, and whose younger sister contracted both diseases almost at the same time; sixteen years later (1909) Mrs. A. had nodal fever again, and her two daughters, aged 14 and 12 years respectively, had it simultaneously in 1921. In another instance a mother was ill with nodal fever and confined to an upstairs room, whilst her grown-up son was laid up with a bubo on the ground floor; when sufficiently well the mother used to come downstairs and sit with her son; he exhibited the rash within a few dars. A young woman, domestic servant, was admitted into the Adelaide
Hospital with the complaint on March 15th; a sister was admitted on March 29th; she had temporarily filled her sister's situation, though she had not slept in the same bed.

Apart from relatives, however, $\mathbf{I}$ have two instanses that are quite striking. No case of nodal fever had been treated in the wards of the Adelaide Children's Hospital for eighteen months until May, 1889, when L. H. and H. D. were admitted on the 9 th and 13 th respectively. T. H. (no relation of $\mathbf{L} . \mathbf{H}$.) was admitted for other reasons on May 4th, and on June 10th he exhibited the rash. In 1909 a young girl was convalescent in the Adelaide Hospital from typhoid; she developed nodal fever, and two of the nurses in attendance on her contracted it, their incubation period being at least eight days.

Of epidemics of nodal fever I hare had no personal experience. Six cases were noticed almost simultaneously at an outlying port in South Australia about thirty years ago. Besides the instances quoted by Dr. Odery Symes, ${ }^{8}$ there is a legend of an outbreak on board a training ship just before the holidays commenced; several cadets, who had apparently escaped infection, had definite attacks after reaching home; this used to be quoted, I am informed, ${ }^{3}$ by Dr. Lees. Moses quotes ${ }^{10}$ an epidemic which occurred in Bosnia in 1857, and Wiborg ${ }^{11}$ describes one in Norway in 1921-22, when he saw 30 cases in ten months, 18 of which occurred in December.

\section{The Relationghip to Other Diseases. Other Forms of Erythema.}

I should not, perhaps, have alluded once more to this branch of the subject were it not that I notice that Dr. Odery Symes, ${ }^{8}$ in his last able contribution, has not fully made up his mind. Personally I had no doubt in 1890 that although Trousseau in his classic lectures ${ }^{12}$ sought to distinguish between erythema rodosum and erythema papulatum, anyone reading his cases carefully must come to the conclusion that the difference was in degree, but not in kind, and that in fact he had unwittingly established their identity. In two severe instances of erythema papulatum occurring in my practice the patients had suffered from erythema nodosum many years previously. whilst associated with undoubted erythema nodosum $I$ have seen at times not only erythema papulatum but every other variety that has been described -erythema tuberculatum, erythema iris, erythema gyratum. Again, in the few cases in which 1 could not demonstrate typical nodes on the legs, the same prodromata, the same high fever, the same arthritic and teno-synovial signs, the same long convalescence, have been noticed. There is nothing of which $I$ am more strongly convinced than of the identity of these separate elements of erythema multiforme, whose differences are merely those of outward form; such compound cases, if one mav so term them, are seen in children occasionally, though less frequently than in adults; in one very severe case of erythema multiforme the infection was traced to another child with the simplest form of erythema nodosum.

Into the question of the supposed relationship of nodal fever to rheumatism I went fully twenty years ago. I pointed out then that Sir Stephen Mackenzie's statisties ${ }^{13}$ were not the result of personal observation, but were derived from the records of four London hospitals and compiled presumably by their medical registrars. I sent Sir Stephen a copy of Nodal Fever with a letter, but received no reply from him. In December, 1908, when travelling up the Nile, I was introduced to Sir Stephen at Assouan, where he often wintered. It was a most interesting and somewhat amusing meeting; he thought that he remembered my name, but I mentioned that I lived in Australia. "A $h$, then," he said, "perhaps wo have been in correspondence." When I explained that it required two to constitute a correspondence, and that he still owed me a letter, he immediately recalled the circumstance, and said that he had been intending to reply for more than eighteen months, and that he thought he had the answer amongst his luggage; however, he had not been able to find the document next day when he came down to the steamer to see me. Shortly after ho died, and I was unable to procure any information as to the document.

Other writers meanwhile, whose opinion carries much 
more weight than mine possibly could, and notably Dr. Odery Symes, ${ }^{14}$ Dr. Maxwell Telling, ${ }^{15}$ and Dr. Hope Gosse, ${ }^{16}$ have gone into the matter carefully and arrived at much the same conclusion as myself. It therefore seems to me to be unnecessary to say more than this-that there are only three cases in my new series in which there is a history of previous rheumatic fever in the patient, and that in none of the three had any organic cardiac lesion persisted; that in four others there was a vague history of socalled rheumatism; and that in only five cases was there a family history of acute rheumatism. Again $I$ wish to emphasize my conviction that the pseudo-rheumatism of nodal fever is an expression of arthritis or of teno-synovitis due directly to the "germ" which causes the skin eruption, or to the toxins to which it may give rise. Above all, I wish to reiterate the absolute uselessness of drugs of the salicylic acid group to ease these pains or to control the course of the disease.

Lastly, roughly speaking, there are no cardiac complications of nodal fever: a transient though distinct murmur may be noted during the illness, but it disappears; it is probably haemic or myocardial.

\section{Tuberculosis.}

When my book was published in 1905 , in disputing the rheumatic theory which then held the field, I lightly said ${ }^{17}$ that it would be just as easy to prove, as far as mere statistics were concerned, that nodal fever was related to tuberculosis. I little dreamt then how large the tuberculous theory of its origin would loom in the next twenty years, though it was broached originally over half a century ago, or that $I$ should read the dogmatic assertion in a retrospect of the year $1918^{18}$ that " the causative factor of erythema nodosum has now been determined to be tuberculosis." The subject, therefore, requires careful investigation. In this direction again I am forestalled by Dr. Symes, and I can only assert that the proportion of tuberculous manifestation preceding nodal fever is not greater in my experience than one would expect considering how widely spread tuberculosis is known to be, and that tuberculous sequelae are comparatively rare. In my whole series there are only two cases of nodal fever complicating tuberculosis-one a girl of 18 who had suffered since early childhood from morbus coxae, and a young married woman who was at the time suffering from, and who subsequently died of, phthisis. A mother, who had lost a son from tuberculous meningitis, died many years later from erythema papulatum, but without any evidence of being tuberculous herself.

\section{Opinions of Other Writers.}

Some writers ${ }^{1920}$ have drawn attention to the fact that nodal fever occasionally follows shortly after measles, and I have notes of one such case. I can hardly think that there is any causal relationship, but the observation is one to be borne in mind.

There are many who still adhere to the rheumatic fever heresy (cf. references 21 to 27), but as a rule they only bring forward one or two isolated cases. Wiborg, 11 however, is an exception, as he recorded an epidemic of thirty cases which he considered to be of rheumatic rather than of tuberculous origin. Hallam ${ }^{28}$ writes in opposition to the rheumatic theory.

Landouzy ${ }^{29}$ excised a node and found in it Koch's bacillus; he inoculated a guinea-pig with a portion of this node and produced in the animal tuberculous lesions, but he does not himself contend that therefore all cases of erythema nodosum are tuberculous in origin. Ward ${ }^{30}$ expresses similar views. Hildebrand ${ }^{29}$ obtained with venous blood similar inoculation results. On the other hand, Otto Brian $^{29}$ induced tuberculosis in a guinea-pig in one experiment, but failed in all his others. His conclusion was that tuberculosis was the actual cause of erythema nodosum in only a few cases; Dufourt ${ }^{31}$ put it as high as 60 per cent. Deléarde and Haller ${ }^{32}$ also think that the greater number of cases arise from a tuberculous soil.

Intradermic injection of tuberculin is $\operatorname{said}^{29}$ to have caused lesions exactly resembling erythema nodosum at the point of injection, but Dr. Darcy Cowan informs me that he can recall no case following hypodermic injection. Stefano $^{33}$ obtained a positive reaction in all the 23 cases in which he tried von Pirquet's test. Vetlesen ${ }^{34}$ plumps for tuberculosis. Several writers have recorded 353629 the fact of cases of erythema nodosum complicating tuberculosis and winding up with meningitis, and have verified their observations by necropsies. Haug ${ }^{37}$ opines that the tubercle bacillus can provoke either erythema nodosum, or a form of arthritis which does not yield to sodium salicylate nor pass so quickly from joint to joint as usual. Meara and Goodridge ${ }^{29}$ thought that erythema nodosum occurred under three conditions: (1) as a simple variety of erythema multiforme; (2) as a definite specific contagious disease; (3) as a lesion secondary to many things, such as infectious diseases, drug ingestion, alimentary disturbance, and nerve diseases.

Lastly, several writers have been impressed with the possible infectious and contagious nature of nodal fever. These include: Anderson and Cooper, ${ }^{38}$ Clarke, ${ }^{39}$ Craig, ${ }^{40}$ Durante $^{41}$ (who excludes tuberculosis and rheumatism), Wendler, ${ }^{42}$ Settgast ${ }^{43}$ (who considers rheumatism a complication, not a cause, and excludes tuberculosis from consideration), Dorth, ${ }^{44}$ and Moses. ${ }^{10}$ Gueissaz $^{45}$ finds it to be an acute exanthem, and that marvellous observer Sir Jonathan Hutchinson ${ }^{46}$ almost said the same thing more than half a century ago. Amongst English writers Odery Symes $^{8}$ bears me out in almost every respect, whilst Maxwell Telling ${ }^{15}$ also considers it to be an acute specific disease, but does not agree with me, I fancy, as to its relationship to erythema multiforme.

\section{REFERENCES.}

1 Australasian Med. Gazette, September, 1890. 2 Nodal Fever, p. 33. s Ibid., p. 40. 'Australasian Med. Gazette, August, 1892. 'Med. Journ. of Australia, January 8th, 1916. ' Nodal Fever, p. $48 .{ }^{7}$ Ibicl., p. 50. British Medical Journal, November 5th, 1921. 9 Letter from Dr. BRris Frederick Langmead. 10 Inaugural Dissertation, Berlin, 1894. 11 BRIrISH MEDICAL JourNal, Epitome, 1923, i, para. $270 .{ }^{12}$ New Sydenham Society's
Translation. ${ }_{13}$ Clinical .Society's Transactions, vol. xix. ${ }^{14}$ Lancet, January 26th, 1907. 15 BRITISH MEDIC.AL JouRNAL, February 13th, 1909: 16 Practitioner, August, 1913. ${ }^{17}$ Nodal Fever, p. 72. ${ }^{18}$ Med. Journ. of Australia, February 1st, 1919. 19 Joynt: British Medical Journal, April 15th, 1911. ${ }^{20}$ Birch : Ibid., April, 1911. ${ }^{21}$ Williams : Ibid., September 2nd. 1911. 22 Neave : Ibid., April 20th, 1912. 23 Watson: Ibid., November 14tin, 1921 24 Van Praagh: Ibid., November 21st, 1921. 25 Wetherbee : Ibid., June 24th, 1922. 26 Holland : Ibid., Epitome, 1922, ii, para. 439. Ibid., June 24th, 1922. 26 Holland: Ibid., Epitome, 1922, ii, para. 439.
27 . 27 Newman : Ibid., May 24th, 1924. 28 Hallam : Ibid., November 21st,
1921. 29 Meara and Goodridge : Amer. Journ. Med. Sci., March, 1912. 30 Ward: British Medical Journal, December 20th, 1919. ${ }_{31}$ Dufourt: Ilid., Epitome, 1923, ii, para. 256. ${ }^{32}$ Deléarde and Hallez : Ibid., Epitome, 1911, ii, para. 201. ${ }^{33}$ La Pediatria, November, 1919. ${ }^{34}$ Tubercle, July, 1922. 35 Howe: British Medical Journal, November 19th, 1921. 36 Dunlop: Ibid., July 20th, 1912. 37 Tubercle, May, 1920. 38 BRITISH Dunlop : Ibid., July 2ath, 1912. 37 Tubercle, May, 1920. 38 BRITISH 10 Ibid., May 20th, 1911. 41 La Pediatria, September, 1912. 42 Inaugural Dissertation, Berlin, 1893. ${ }^{43}$ Inaugural Dissertation, Griefswald, 1890. 4 Inaugural Dissertation, Würzburg, 1891. 45 British Medical Joursal, Epitome, 1922, i, para. 55. $40 \mathrm{Med}$. Times and Gazette, 1869.

\section{THE CHEMOTHERAPEUTIC TREATMENT OF GONORRHOEA AND ITS COMPLICATIONS.* \\ BY}

\section{J. E. R. McDONAGH, F.R.C.S.,} SURGEON TO THE LONDON LOCK HOSPITAL.

\section{Introduction.}

Tнобан gonorrhoea, when first contracted, is a local infection, nevertheless changes do occur in the blood of the host, particularly in the protein particles of the plasma in which resides the host's main protective substance. Treatment with . chemical substances and protein extracts (vaccines) acts by increasing the patient's resistance and not by killing the invading micro-organisms directly. Considering that vaccine treatment alone leaves much to be desired, it has been my endeavour for some years past to find a chemical compound which would have much the same effect in gonorrhoea as has arsenobenzene in syphilis.

The last milestone in this work was marked by the introduction of manganese butyrate, a drug which has proved

* A post-graduate lecture given at the London Lock Hospital, February 